\title{
Gross motor function and health fitness in adults with autistic spectrum disorder and intellectual disability: single-blind retrospective trial
}

\author{
Jun-Youl Cha ${ }^{1,3}$, Su-Kyung Min ${ }^{2,3}$, Tae-Hyun Yoon ${ }^{3}$, Yong-Seok Jee $e^{3, *}$ \\ ${ }^{1}$ Division of Martial Arts · Guard, Howon University, Gunsan, Korea \\ ${ }^{2}$ Department of Physical Education, Chungbuk National University, Chungju, Korea \\ ${ }^{3}$ Research Institute of Sports and Industry Science (RISIS), Hanseo University, Seosan, Korea
}

This study aimed at providing an exercise program for each type of disability after analyzing the exercise program performed by adults with intellectual disability (ID) or autistic spectrum disorder (ASD). Twentynine male adults voluntarily took part in this study, whose age ranged from 19 to 28 years and with an average body mass index of $23.98 \pm$ $4.02 \mathrm{~kg} / \mathrm{m}^{2}$. The sample was divided into two groups as follows: ASD group ( $A S D G ; n=15$ ) and ID group (IDG, $n=14$ ). The selected tests used to measure gross motor function (GMF, locomotion and object control skills) and health fitness (body composition, flexibility, strength, muscle endurance, and cardiopulmonary endurance) were also used in previous studies. The GMF and health fitness between ASDG and IDG showed no significant differences. This study indicates that exercise programs could provide similar effects, even with other disorder types having similar symptoms.

Keywords: Autistic spectrum disorder, Intellectual disability, Gross motor function, Health fitness

\section{INTRODUCTION}

Intellectual disability (ID) and autism spectrum disorders (ASD) are neurodevelopmental disorders that affect daily living due to impaired adaptive and intellectual functions (Matson et al., 2008; Totsika et al., 2010). ASD and ID improve as the child grows older, but some entail impairments throughout life. Both ASD and ID are affected by heredity and males account for a higher percentage than females. Most research studies on ASD have shown prevalence figures using data from child cohorts. There has been a steady rise in the prevalence of ASD in children, with an estimated $5 \%$ of child subjects from studies conducted from the mid-1990s onward (Baird et al., 2006).

Until recently, no epidemiologic studies in adults, including ID, have been done. However, Brugha et al. (2011) looked into ASD in adults based on an adult psychiatric morbidity survey from the
United Kingdom. From their study, prevalence rates were confirmed to be approximately $1 \%$, but showed a higher prevalence rate in men $(1.8 \%)$ than in women $(0.2 \%)$. There was a higher likelihood for people with ASD and ID to be poorly educated, unmarried, and economically deprived compared to the general population (Howlin and Moss, 2012). In other words, adults who are mentally retarded are psychologically and socially vulnerable. The severity of both ID and ASD was determined by social awareness and communication. Generally, ASD is classified as mild, moderate, and severe, while the severity of ID is divided into four stages. Pedersen et al. (2017) reported that people who have ASD tend to exhibit a greater deficiency in nonverbal social behavior, which includes body language and the understanding of social cues. Matson and Dempsey (2008) found that subjects with ID displayed less repetitive behaviors. When compared to subjects with ID, those with ASD were reported to be more likely to self-isolate and
*Corresponding author: Yong-Seok Jee (iD https://orcid.org/0000-0001-6797-0843 Research Institute of Sports and Industry Science (RISIS), Hanseo University, 46 Hanseo 1-ro, Haemi-myeon, Seosan 31962, Korea

E-mail: jeeys@hanseo.ac.kr

Received: April 1, 2020 / Accepted: April 27, 2020
This is an Open Access article distributed under the terms of the Creative Commons Attribution Non-Commercial License (https://creativecommons.org/licenses/by-nc/4.0/) which permits unrestricted non-commercial use, distribution, and reproduction in any medium, provided the original work is properly cited. 
to avoid eye contact. Several researchers reported a high likelihood of accompanying or overlapping ASD and ID (Matson and Shoemaker, 2009; Wilkins and Matson, 2009). Higashida et al. (2019) speculated that people with ID may go unnoticed in regards to co-occurring ASD. Actually, people with both ASD and ID have different needs compared to those with only either ASD or ID (Carminati et al., 2007; Gilchrist et al., 2001).

As such, ASD and ID share clinical characteristics which could result in confusion during diagnosis (Pedersen et al., 2017). It is possible that people with ASD that exhibit symptoms of ID may inadvertently be codiagnosed, which could result in receiving treatment for a nonexistent condition. Likewise, there is also the chance that people with ID may be misdiagnosed to have ASD and wrongly receive treatment for a condition they do not have. Clearly distinguishing the differences between ASD and ID will allow for the prescription of the appropriate treatments (Matson and Shoemaker, 2009).

Various treatment methods from several studies have been shown to improve symptoms (Bahrami et al., 2012). A growing body of evidence provides added support that regular physical activity has positive effects, such as improved respiratory function (Khalili and Elkins, 2009), reduced depression and anxiety, an enhanced sense of well-being, and better performance at work (Croce and Horvat, 1992). Several studies point to the importance of maintaining health and physical activity for people with ID and similar conditions (Chanias et al., 1998; Jansen et al., 2004). Among the outcome measures often used in early intervention programs are changes in the intelligence quotient (IQ). A lower IQ indicates a poorer prognosis for early intensive plans (Ben Itzchak et al., 2008; Matson and Smith, 2008). Verschuren et al. (2016) recently reported that engaging in physical activity can improve body image and help with treatment. Physical activity provides children with developmental disabilities with opportunities for physical development, reduces stress and anxiety, and improves muscle functions that helps for improved safety.

It is difficult to clearly distinguish between symptoms in individuals with ASD or ID. Although, major advances have been made in regards to the diagnosis, causes, and treatment for children with such conditions, there is a lack of research on the prognosis, results, and effective interventions for adults (Howlin and Moss, 2012). Even in Korea, physical activity programs for adults with ASD or ID were provided by various institutions, but no detailed program was provided depending on the type of disability. In addition, most play and exercise programs related to the disability were focused only on children, but programs that take into account the charac- teristics of adults were not provided. Therefore, this study aimed to provide an exercise program for each type of disability after analyzing the exercise program performed by an adult with ASD or ID in a developmental disability center. In other words, this study analyzed the differences in gross motor function (GMF) and health fitness in participants who took part in the same exercise program for one year among adults with ASD or ID.

\section{MATERIALS AND METHODS}

\section{Subjects}

The voluntary participants included male adults from 19 to 28 years of age. For inclusion, participants were required to enroll in the research center for motor development, have ASD or ID, and have regularly exercised for the past twelve months. All participants took part in a supervised physical activity program for 2 days (Tuesday and Friday) a week for a year. They began with warm-up conditioning for 5 min by a practitioner. Next, they performed up to five types of work-out sessions, which was composed of routine games (basic locomotion skill, catching a tail, playing tug-of-war), floorball games (routine exercise for passing and receiving a ball, passing practice, mini-short game), basketball (dribble a ball, pass a ball, shoot a ball), and inline skating (basic skating skill, walking, pushing, turning) for 40 to $45 \mathrm{~min}$. Finally, they finished their program with 10 min of stretching.

Based on the criteria above, 32 subjects were screened to determine eligibility. Among them, three subjects refused to participate. In the end, 29 subjects took part in this study. Subjects with hearing, visual, and/or physical disabilities were excluded from the study. Furthermore, subjects unable to be measured or unable to continue, as well as those who have received medical treatment affecting physical condition, including any major surgery in the past year, were excluded from the study. Finally, all subjects were divided into autistic spectrum disorder group (ASDG, $\mathrm{n}=15$ ) and ID group (IDG, $\mathrm{n}=14$ ) as shown in Table 1 .

Table 1. Physical characteristics of the subjects

\begin{tabular}{lcccc}
\hline Variable & $\mathrm{ASD}(\mathrm{n}=15)$ & $\mathrm{ID}(\mathrm{n}=14)$ & $\mathrm{Z}$ & $P$-value \\
\hline Age $(\mathrm{yr})$ & $22.22 \pm 2.31$ & $21.93 \pm 2.87$ & -0.595 & 0.561 \\
Height $(\mathrm{cm})$ & $171.36 \pm 5.47$ & $169.55 \pm 7.79$ & -0.372 & 0.715 \\
Weight $(\mathrm{kg})$ & $71.21 \pm 13.05$ & $69.31 \pm 12.25$ & -0.393 & 0.713 \\
Body mass index $\left(\mathrm{kg} / \mathrm{m}^{2}\right)$ & $24.02 \pm 4.52$ & $23.95 \pm 3.58$ & -0.240 & 0.813 \\
Symptom & $1.60 \pm 0.51$ & $1.43 \pm 0.51$ & -0.907 & 0.451
\end{tabular}

Values are expressed as mean \pm standard deviation. ASD, autism spectrum disorder; ID, intellectual disability. 


\section{Experimental protocol}

This was a single-blind, retrospective trial, which used the exercise program as the independent variable, and GMF and health fitness as the dependent variables. The assessment was conducted from February 13 to 14, 2020. The participants, including their parents, were continuously given motivation and encouragement to complete all the tests. Advertisements were used to recruit the subjects who signed an informed consent before the start of the study, which was approved by the ethics committee and done according to the Declaration of Helsinki (2-7001793-AB-N-012019113HR).

\section{Test of gross motor development}

This study used the test of gross motor development scale-2 (TGMD-2), which is a standardized criterion that measures GMF changes in disabled persons according to Yoon et al. (2019). Reliability of this test was found to be Cronbach $\mathrm{a}=0.894$. Twelve patterns of major muscle movements were divided into two parts: locomotion skills and object control skills. Horizontal jumping, hopping, galloping, leaping, running, and sliding comprised the locomotion section. Hitting a fixed ball, kicking a ball, catching a ball, stationary dribbling a ball, underhand rolling a ball, and overhand throwing a ball comprised of the object control skills. After examining the TGMD-2, one point was given if they were able to complete the task, while no point was given if they were unable to do the task. The total score, using subscales, was obtained from adding the results of the two parts (Allen et al., 2017). The locomotion and object control sections each had a maximum score of 48 points from the six subscales. Using the TGMD-2 is simple and useful for finding areas of improvement in exercise programs. Physical education experts often use it to create individualized training programs (Bittner, 2018).

\section{Test of health physical fitness}

Bioelectrical impedance analysis method assessed by Body Composition Analyzer (InBody 230, BioSpace, Seoul, Korea) was used to measure body composition and a height tester was used to measure height (Analogue height tester, Samwha, Seoul, Korea). The body composition analyzer is a segmental impedance device that has electrodes made of stainless steel interfaces. The subjects stood on the foot electrodes as they stood upright, without holding the handles. Analysis of height and body weight was measured prior to dinner and after emptying (Cha et al., 2014). The variables from body composition were body mass index (BMI), muscle mass, fat mass, waist/hip ratio (WHR), and basal metabolic rate (BMR).
The sit and reach flexion test was used to measure flexibility with a measuring device (TKK1859, Takei Inc., Tokyo, Japan). A ruler ( $25 \mathrm{~cm}$ outwards, $40 \mathrm{~cm}$ inwards) was attached to the surface perpendicularly. The heels of the subjects were placed against the platform at a distance of $5 \mathrm{~cm}$ apart. After taking a deep breath, the subjects bent forward and extended their fingertips to the furthest possible point as they exhaled. Subjects were told to refrain from bouncing their waist while bending forward. Their legs were kept straight with their heads between their arms as they reached forward. Two measurements were taken with the greatest distance being recorded.

Strength was measured using a digital hand dynamometer (TKK5401, Takei Inc.) that measures grip strength. Participants sat in a chair with their shoulder positioned at $0^{\circ}$ flexion and elbow at $90^{\circ}$ flexion. Their wrist was between supination and pronation and the hand positioned vertically. The subjects placed the middle phalanges on the handle of the dynamometer and squeezed 3 times with maximum force with a minute of rest between each attempt. The greatest amount of force produced from 6 attempts was recorded and converted to kilograms. In order to ensure that the subjects exerted their greatest effort, the test examiner took into account the muscles contractions of the arm and hand, color changes in the phalanges, changes in facial expressions, and consistency of each trial. The grip strength of the left and right sides was summed and recorded as the average value.

A customized sit-up test was used to measure muscle endurance. The subjects lied on a mat, locked their hands behind their heads, and positioned their feet $30 \mathrm{~cm}$ apart with their knees bent at $90^{\circ}$ as their ankles were held down by an assistant. When the signal was given, the subjects moved their upper body forward and touched their knees with their elbows. To count as one sit-up, the back had to touch the floor after both elbows touched the knees. The highest count during one minute was recorded.

A $15-\mathrm{m}$ shuttle run test was used to measure cardiopulmonary endurance, which is commonly used as an aerobic fitness test. This is also referred to as a bleep test or multi-stage fitness test (Yoon et al., 2019). Before beginning the test, the subjects were explained the test procedures by an expert and instructed to complete warmups. The subjects were positioned behind a line that faced a second line $15 \mathrm{~m}$ apart. At each beep, the subjects ran toward the other line. The beep intervals were long in the beginning, but became shorter after about one min, which increased the pace. This increase in pace continued on for each following minute (level). In the case that the subject reached the line before the next beep, they waited until the beep before running again. For those who did not reach 
the line before the beep, they were issued a warning as they continued to run and attempt to catch up within the next 2 beeps. The first warning was given for failing to reach the line (within $2 \mathrm{~m}$ ) and were eliminated after being given a second warning. The recorded score was calculated as the total number of shuttles completed before being eliminated.

\section{Statistical analysis}

The results obtained through the experiment were input using Microsoft Excel (Microsoft, Redmond, WA, USA), and calculated using technical statistics (mean \pm standard deviation). The IBM SPSS ver. 18.0 (IBM Co., Armonk, NY, USA) was used to calculate statistics for this study. Based on the results of the ShapiroWilk test, an independent $t$-test was performed to compare the differences of variables between ASDG and IDG. At this time, Mann-Whitney $U$-test, which is a nonparametric statistic, was used for data for which the normality of distribution for the examined variables was not confirmed, and the statistical significance level of this study was set at 0.05 .

\section{RESULTS}

\section{Comparison of demographic factors}

All subjects were aged 19 to 28 years, their mean age was $22.07 \pm$ 2.55 years old, and mean BMI was $23.98 \pm 4.02 \mathrm{~kg} / \mathrm{m}^{2}$ as shown in Table 1. Symptom degrees between groups were not significantly different. The mild symptom and severe symptom of ASDG

Table 2. Comparative results of gross motor function between groups

\begin{tabular}{lrccc}
\hline Variable & ASD $(\mathrm{n}=15)$ & $\mathrm{ID}(\mathrm{n}=14)$ & $Z$ & $P$-value \\
\hline Run & $5.40 \pm 2.44$ & $4.64 \pm 2.98$ & -0.668 & 0.533 \\
Gallop & $6.60 \pm 1.24$ & $6.07 \pm 1.33$ & -0.985 & 0.354 \\
Hop & $6.27 \pm 1.75$ & $6.14 \pm 2.57$ & -0.112 & 0.914 \\
Leap & $5.80 \pm 0.86$ & $5.29 \pm 1.38$ & -0.829 & 0.505 \\
Horizontal Jump & $3.40 \pm 3.00$ & $4.36 \pm 2.65$ & -1.075 & 0.310 \\
Slide & $7.13 \pm 0.99$ & $7.21 \pm 1.19$ & -0.506 & 0.652 \\
Locomotion skill & $34.73 \pm 7.44$ & $33.86 \pm 10.11$ & -0.175 & 0.880 \\
Striking a ball & $3.73 \pm 1.33$ & $3.64 \pm 0.93$ & -0.056 & 0.983 \\
Dribbling a ball & $6.40 \pm 2.35$ & $6.07 \pm 2.56$ & -0.217 & 0.847 \\
Catching a ball & $4.87 \pm 1.41$ & $4.86 \pm 1.66$ & -0.185 & 0.880 \\
Kicking a ball & $5.40 \pm 1.68$ & $5.14 \pm 1.79$ & -0.269 & 0.813 \\
Over-throwing a ball & $0.07 \pm 0.26$ & $0.14 \pm 0.36$ & -0.662 & 0.747 \\
Under-rolling a ball & $3.60 \pm 2.13$ & $3.79 \pm 2.12$ & -0.380 & 0.715 \\
Object control skill & $24.07 \pm 5.87$ & $23.64 \pm 6.82$ & 0.001 & 1.000
\end{tabular}

Values are expressed as mean \pm standard deviation. ASD, autism spectrum disorder; ID, intellectual disability. were 11 and 4, respectively. The mild symptom and severe symptom of IDG were 9 and 5, respectively.

\section{Differences of GMF between groups}

As shown in Table 2, the six variables of locomotion skill were not significantly different between ASDG and IDG. There were no significant differences in the sum of locomotion skills between groups. Similarly, these results from the six variables and sum score of object control skills were not significantly different between both groups.

\section{Difference of body composition between groups}

As Table 3 shows, there was no significant difference in muscle mass between ASDG and IDG. Although the value of IDG was shown to have a higher tendency, there was no significant difference in fat mass between both groups. WHR was not significantly different between ASDG and IDG after completing the physical activity program. Finally, there was no significant difference in BMR between both groups, although the value of ASD group was shown to have a higher tendency.

\section{Differences of physical fitness between groups}

As shown in Table 4, flexibility $(P=0.310)$, strength $(P=0.681)$, muscle endurance $(P=0.441)$, and cardiopulmonary endurance $(P=0.123)$ showed no significant differences between ASDG and IDG after completing the physical activity program.

Table 3. Comparative results of body composition between groups

\begin{tabular}{lrccc}
\hline Variable & $\mathrm{ASD}(\mathrm{n}=15)$ & $\mathrm{ID}(\mathrm{n}=14)$ & \multicolumn{1}{c}{$Z$} & $P$-value \\
\hline Muscle mass $(\mathrm{kg})$ & $50.05 \pm 6.87$ & $47.41 \pm 8.2$ & -0.722 & 0.477 \\
Fat mass $(\mathrm{kg})$ & $22.31 \pm 7.96$ & $23.79 \pm 7.39$ & -0.131 & 0.914 \\
WHR & $0.8 \pm 0.09$ & $0.8 \pm 0.07$ & -0.220 & 0.847 \\
BMR (kcal/day) & $1,533.53 \pm 151.6$ & $1,481.57 \pm 181.38$ & -0.721 & 0.477 \\
\hline
\end{tabular}

Values are expressed as mean \pm standard deviation.

ASD, autism spectrum disorder; ID, intellectual disability; WHR, waist/hip ratio; BMR, basal metabolic rate.

Table 4. Comparative results of physical fitness between groups

\begin{tabular}{lrrrc}
\hline Variable & ASD $(n=15)$ & $\mathrm{ID}(n=14)$ & $Z$ & $P$-value \\
\hline Flexibility $(\mathrm{cm})$ & $-5.83 \pm 4.05$ & $-3.18 \pm 6.33$ & -1.072 & 0.310 \\
Strength $(\mathrm{kg})$ & $17.57 \pm 4.24$ & $18.09 \pm 4.79$ & -0.415 & 0.683 \\
Muscle endurance (reps) & $13.86 \pm 5.21$ & $13.24 \pm 5.31$ & -0.603 & 0.441 \\
Cardiopulmonary endurance (reps) & $7.86 \pm 4.35$ & $7.24 \pm 2.17$ & -1.586 & 0.123
\end{tabular}

Values are expressed as mean \pm standard deviation. ASD, autism spectrum disorder; ID, intellectual disability. 


\section{DISCUSSION}

This study analyzed the differences in GMF and health fitness in participants who took part in the same exercise program for a year among adults with ID or ASD. From the results of this study, no significant differences existed in GMF and health fitness between ASDG and IDG. In other words, a year-long exercise program did not provide a difference in disability type. The result showed that exercise programs could provide similar results, even with other disorder types with similar symptoms. In fact, this study was a retrospective study comparing variables between two groups with postvalue only after a year of exercise without prevalue. Therefore, it was not known whether health fitness and GMF increased or decreased.

Many researchers have reported that adults with mental retardation have lesser adaptive, cognitive, and social skills. Individuals with developmental disability also have more limited physical abilities compared to those who do not. Moreover, they are often accompanied by stereotype and challenging behavior such as depression, anxiety, and schizophrenia (Downs et al., 2008; Holden and Gitlesen, 2008; Lee et al., 2008; Lifshitz et al., 2008; Matson et al., 2005; McGillivray et al., 2008; Myrbakk and von Tetzchner, 2008; Thirion-Marissiaux and Nader-Grosbois, 2008; Yalon-Chamovitz and Weiss, 2008; Zayac and Johnston, 2008). All of these problems could be problematic for patients, their family, and even society. Specifically, individuals with developmental disability, on average, score $25 \%$ less on developmental tests than those without (Wood et al., 2000). In other words, there is no physical fitness test for the disabled and only exercise programs are provided. According to several previous studies, there are many reports that people with disabilities who have good physical fitness or enjoy sports have increased psychological stability and improved sociality. However, as described above, if the program was provided after the physical examination was performed, it may provide better results. In other words, a lot of researchers reported that a physical activity or an exercise program provided to adults with mental retardation has been reported to promote psychological health as well as physical health of persons with disabilities and play a role in society (Chanias et al., 1998; Croce and Horvat, 1992; Jansen et al., 2004; Rimmer, 1999; Verschuren et al., 2016). A review on studies involving the mental health and physical fitness of both able and disabled populations showed that physical activity led to improved psychological states in children with ID (Folkins and Sime, 1981). Gabler-Halle et al. (1993) found that aerobic exercise led to many improvements in psychological variables such as behavior, self-concept, and intellectual functioning.

Especially, a variety of programs are offered to help children with mental retardation grow into members of society. Among them are physical activity programs that could improve the health of children with disabilities, promote psychological stability, and increase the chances of social adjustment (Ahn and Fedewa, 2011; Janssen and LeBlanc, 2010; Latorre Román et al., 2015). The effects of physical activity in children with developmental disabilities include improved physical development and muscle function necessary to protect the body (Verschuren et al., 2016). Body fat distribution and physical fitness in childhood are highly correlated with cardiovascular health in adulthood. Bürgi et al. (2011) indicated that preschoolers who are physically active tend to have improved aerobic capacity and heart function. These findings show that childhood fitness levels have important long-term effects on health. (Ortega et al., 2008; Ortega et al., 2015). For adults with ASD or ID, physical activity not only provides available movement, but also improves physical function and mental pleasure. In other words, since physical activity itself is learning and living, it is essential for the education of adults with mental disabilities.

Lower levels of muscular strength and cardiovascular fitness and higher levels of obesity were found in individuals with ID compared to those without. (Pitetti and Yarmer, 2002; Pitetti et al., 2001). For people with ID, Frey et al. (2008) showed that physical fitness performance is significantly lower, while Frey et al. (2008) reported less physical activity than those without ID (Van den Berg-Emons et al., 1998). Similarly, a meta-analysis was conducted by Chanias et al. (1998) to analyze the effects of physical activity on fitness levels in people with ID. Data was gathered from 21 studies yielding an effect size of 100. Significant effects were shown in areas of cardiovascular and muscular endurance, moderate effects for muscular strength, less notable effects for flexibility, and insignificant effects for body composition. In addition, they reported that program type influenced strength and program frequency influenced flexibility.

In conclusion, no significant differences were found in the GMF and health fitness between ASDG and IDG in this study. In other words, a year-long exercise program did not provide a difference in disability type, but the BMR of ASDG was higher tendency than that of IDG. The result showed that exercise programs could provide similar results, even with other disorder types with similar symptoms. Specifically, this study includes some limitations as follows. First, the experiment was conducted by selecting a special education institute, as such, it was difficult to generalize the research results to all adults with disabilities. Second, the adults were 
not able to control the physical other activities and eating methods. Revising the standards of reporting relevant data related to samples and exercise prescription components would be beneficial for future research studies.

\section{CONFLICT OF INTEREST}

No potential conflict of interest relevant to this article was reported.

\section{ACKNOWLEDGMENTS}

This study was supported by the Research Grant of Howon University in 2020.

\section{REFERENCES}

Ahn S, Fedewa AL. A meta-analysis of the relationship between children's physical activity and mental health. J Pediatr Psychol 2011;36:385-397.

Allen KA, Bredero B, Van Damme T, Ulrich DA, Simons J. Test of gross motor development-3 (TGMD-3) with the use of visual supports for children with autism spectrum disorder: validity and reliability. J Autism Dev Disord 2017;47:813-833.

Bahrami F, Movahedi A, Marandi SM, Abedi A. Kata techniques training consistently decreases stereotypy in children with autism spectrum disorder. Res Dev Disabil 2012;33:1183-1193.

Baird G, Simonoff E, Pickles A, Chandler S, Loucas T, Meldrum D, Charman T. Prevalence of disorders of the autism spectrum in a population cohort of children in South Thames: the Special Needs and Autism Project (SNAP). Lancet 2006;368:210-215.

Ben Itzchak E, Lahat E, Burgin R, Zachor AD. Cognitive, behavior and intervention outcome in young children with autism. Res Dev Disabil 2008;29:447-458.

Bittner M. Developmental and adapted physical activity assessment, 2nd edition. Adapt Phys Activ Q 2018;35:498-500.

Brugha TS, McManus S, Bankart J, Scott F, Purdon S, Smith J, Bebbington $P$, Jenkins R, Meltzer H. Epidemiology of autism spectrum disorders in adults in the community in England. Arch Gen Psychiatry 2011;68: 459-465.

Bürgi F, Meyer U, Granacher U, Schindler C, Marques-Vidal P, Kriemler S, Puder JJ. Relationship of physical activity with motor skills, aerobic fitness and body fat in preschool children: a cross-sectional and longitudinal study (Ballabeina). Int J Obes (Lond) 2011;35:937-944

Carminati GG, Gerber F, Baud MA, Baud O. Evaluating the effects of a structured program for adults with autism spectrum disorders and intellectual disabilities. Res Autism Spectr Disord 2007;1:256-265.

Cha JY, Kim JH, Hong J, Choi YT, Kim MH, Cho JH, Ko IG, Jee YS. A 12week rehabilitation program improves body composition, pain sensation, and internal/external torques of baseball pitchers with shoulder impingement symptom. J Exerc Rehabil 2014;10:35-44.

Chanias AK, Reid G, Hoover ML. Exercise effects on health-related physical fitness of individuals with an intellectual disability: a meta-analysis. Adapt Phys Activ Q 1998;15:119-140.

Croce RV, Horvat M. Effects of reinforcement based exercise on fitness and work productivity in adults with mental retardation. Adapt Phys Activ Q 1992;9:148-178.

Downs A, Downs RC, Rau K. Effects of training and feedback on Discrete Trial Teaching skills and student performance. Res Dev Disabil 2008; 29:235-246

Folkins $\mathrm{CH}$, Sime WE. Physical fitness training and mental health. Am Psychol 1981;36:373-389.

Frey GC, Stanish HI, Temple VA. Physical activity of youth with intellectual disability: review and research agenda. Adapt Phys Activ Q 2008; 25:95-117.

Gabler-Halle D, Halle JW, Chung YB. The effects of aerobic exercise on psychological and behavioral variables of individuals with developmental disabilities: a critical review. Res Dev Disabil 1993;14:359-386.

Gilchrist A, Green J, Cox A, Burton D, Rutter M, Le Couteur A. Development and current functioning in adolescents with Asperger syndrome: a comparative study. J Child Psychol Psychiatry 2001;42:227-240.

Higashida H, Munesue T, Kosaka H, Yamasue H, Yokoyama S, Kikuchi M. Social interaction improved by oxytocin in the subclass of autism with comorbid intellectual disabilities. Diseases 2019;7:24.

Holden B, Gitlesen JP. The relationship between psychiatric symptomatology and motivation of challenging behaviour: a preliminary study. Res Dev Disabil 2008;29:408-413.

Howlin P, Moss P. Adults with autism spectrum disorders. Can J Psychiatry 2012;57:275-283.

Jansen DE, Krol B, Groothoff JW, Post D. People with intellectual disability and their health problems: a review of comparative studies. J Intellect Disabil Res 2004;48(Pt 2):93-102.

Janssen I, LeBlanc AG. Review systematic review of the health benefits of physical activity and fitness in school-aged children and youth. Int J Behav Nutr Phy 2010;7:1-16.

Khalili MA, Elkins MR. Aerobic exercise improves lung function in children with intellectual disability: a randomised trial. Aust J Physiother 2009;55:171-175.

Latorre Román PÁ, Mora López D, Fernández Sánchez M, Salas Sánchez J, Moriana Coronas F, García-Pinillos F. Test-retest reliability of a fieldbased physical fitness assessment for children aged 3-6 years. Nutr 
Hosp 2015;32:1683-1688.

Lee LC, Harrington RA, Chang JJ, Connors SL. Increased risk of injury in children with developmental disabilities. Res Dev Disabil 2008;29: 247-255.

Lifshitz H, Merrick J, Morad M. Health status and ADL functioning of older persons with intellectual disability: community residence versus residential care centers. Res Dev Disabil 2008;29:301-315.

Matson JL, Dempsey T. Stereotypy in adults with autism spectrum disorders: relationship and diagnostic fidelity. J Dev Phys Disabil 2008;20: 155-165.

Matson JL, Dixon DR, Matson ML, Logan JR. Classifying mental retardation and specific strength and deficit areas in severe and profoundly mentally retarded persons with the MESSIER. Res Dev Disabil 2005; 26:41-45.

Matson JL, Shoemaker M. Intellectual disability and its relationship to autism spectrum disorders. Res Dev Disabil 2009;30:1107-1114.

Matson JL, Smith KRM. Current status of intensive behavioral interventions for young children with autism and PDD-NOS. Res Autism Spectr Disord 2008;2:60-74.

Matson JL, Wilkins J, Boisjoli JA, Smith KR. The validity of the autism spectrum disorders-diagnosis for intellectually disabled adults (ASDDA). Res Dev Disabil 2008;29:537-546.

McGillivray JA, McCabe MP, Kershaw MM. Depression in people with intellectual disability: an evaluation of a staff-administered treatment program. Res Dev Disabil 2008;29:524-536.

Myrbakk E, von Tetzchner S. Psychiatric disorders and behavior problems in people with intellectual disability. Res Dev Disabil 2008;29: 316-332.

Ortega FB, Cadenas-Sánchez C, Sánchez-Delgado G, Mora-González J, Martínez-Téllez B, Artero EG, Castro-Piñero J, Labayen I, Chillón P, Löf M, Ruiz JR. Systematic review and proposal of a field-based physical fitness-test battery in preschool children: the PREFIT battery. Sports Med 2015;45:533-555.

Ortega FB, Ruiz JR, Castillo MJ, Sjöström M. Physical fitness in childhood and adolescence: a powerful marker of health. Int J Obes (Lond) 2008; 32:1-11.

Pedersen AL, Pettygrove S, Lu Z, Andrews J, Meaney FJ, Kurzius-Spencer M, Lee LC, Durkin MS, Cunniff C. DSM criteria that best differentiate intellectual disability from autism spectrum disorder. Child Psychiatry Hum Dev 2017;48:537-545.

Pitetti KH, Yarmer DA. Lower body strength of children and adolescents with and without mild mental retardation: a comparison. Adapt Phys Activ Q 2002;19:68-81.

Pitetti KH, Yarmer DA, Fernhall B. Cardiovascular fitness and body composition in children and adolescents with and without mental retardation. Adapt Phys Activ Q 2001;18:127-141.

Rimmer JH. Health promotion for people with disabilities: the emerging paradigm shift from disability prevention to prevention of secondary conditions. Phys Ther 1999;79:495-502.

Thirion-Marissiaux AF, Nader-Grosbois N. Theory of mind "beliefs", developmental characteristics and social understanding in children and adolescents with intellectual disabilities. Res Dev Disabil 2008;29:547566.

Totsika V, Felce D, Kerr M, Hastings RP. Behavior problems, psychiatric symptoms, and quality of life for older adults with intellectual disability with and without autism. J Autism Dev Disord 2010;40:1171-1178.

Van den Berg-Emons RJ, Van Baak MA, Speth L, Saris WH. Physical training of school children with spastic cerebral palsy: effects on daily activity, fat mass and fitness. Int J Rehabil Res 1998;21:179-194.

Verschuren O, Peterson MD, Balemans AC, Hurvitz EA. Exercise and physical activity recommendations for people with cerebral palsy. Dev Med Child Neurol 2016;58:798-808.

Wilkins J, Matson JL. A comparison of social skills profiles in intellectually disabled adults with and without ASD. Behav Modif 2009;33:143-155.

Wood NS, Marlow N, Costeloe K, Gibson AT, Wilkinson AR. Neurologic and developmental disability after extremely preterm birth. EPICure Study Group. N Engl J Med 2000;343:378-384.

Yalon-Chamovitz S, Weiss PL. Virtual reality as a leisure activity for young adults with physical and intellectual disabilities. Res Dev Disabil 2008; 29:273-287.

Yoon TH, Mun YK, Lee JS, Min SK, Jee YS. Analysis for reliability and validity of gross motor function and health fitness tests for children with developmental disabilities. J Exerc Rehabil 2019;15:667-675.

Zayac RM, Johnston JM. Contriving establishing operations: responses of individuals with developmental disabilities during a learning task. Res Dev Disabil 2008;29:202-216. 